\title{
EL PENSAMIENTO CRÍTICO EN LA TEORÍA EDUCATIVA CONTEMPORÁNEA \\ CRITICAL THINKING IN CONTEMPORARY EDUCATIONAL THEORY
}

\author{
Volumen 14, Número 2 \\ Mayo - Agosto \\ pp. 1-23
}

Este número se publicó el 30 de mayo de 2014

Luis Carlos Morales Zúñiga

Revista indizada en REDALYC, SCIELO

Revista distribuida en las bases de datos:

CATÁLOGO DE LATINDEX, IRESIE, CLASE, DIALNET, DOAJ, E-REVIST@S, SHERPA/ROMEO, QUALIS, MIAR

Revista registrada en los directorios:

ULRICH'S, REDIE, RINACE, OEI, MAESTROTECA, PREAL, CLASCO 


\title{
EL PENSAMIENTO CRÍTICO EN LA TEORÍA EDUCATIVA CONTEMPORÁNEA

\author{
CRITICAL THINKING IN CONTEMPORARY EDUCATIONAL THEORY
}

\section{Luis Carlos Morales Zúñiga ${ }^{1}$}

\begin{abstract}
Resumen: En este ensayo se reflexiona sobre el lugar que ocupa el pensamiento crítico en la teoría educativa contemporánea. Para lograrlo, se parte de establecer una definición sobre la noción de pensamiento crítico, con el fin de analizar hasta qué punto las corrientes de la teoría educativa crítica y la pedagogía crítica incorporan esta forma particular de razonamiento. Finalmente se plantean algunas limitaciones que poseen el pensamiento crítico y a la educación crítica, con el fin de contribuir al debate contemporáneo sobre esta forma de razonamiento.
\end{abstract}

Palabras clave: PENSAMIENTO CRÍTICO, PEDAGOGÍA CRÍTICA, TEORIA EDUCATIVA

\begin{abstract}
This essay presents a discussion about the place of the critical thought within the contemporary educational theory. It states a definition on the category known as critical thought, in order to analyze how critical educational theory and critical pedagogy, fit in the critical thought concept. Finally, it argues on the limits and critics to the critical thought and critical education, with the purpose of give a contribution to the contemporary debates on this particular way of thinking.
\end{abstract}

Keywords: CRITICIAL THINKING, CRITICAL PEDAGOGY, EDUCATIONAL THEORY.

\footnotetext{
${ }^{1}$ Profesor de la Escuela de Formación Docente, Universidad de Costa Rica. Magíster Scientiae en Sociología por la Maestría Centroamericana en Sociología con sede en la Universidad de Costa Rica. Licenciado en la Enseñanza de los Estudios Sociales y la Educación Cívica.
}

Dirección electrónica: luis23m@gmail.com

Ensayo recibido: 2 de setiembre, 2013

Devuelto para corrección: 10 de febrero, 2014

Aprobado: 15 de mayo, 2014 


\section{Introducción}

Dentro de la teoría educativa contemporánea existen corrientes de pensamiento que siempre están presentes. No es posible prescindir, en la discusión teórica sobre fenómenos educativos, de las tendencias como el constructivismo, el conductismo, el neo institucionalismo, la teoría y el enfoque curricular de competencias, el marxismo, las neurociencias, el funcionalismo, las teorías reproduccionistas, o bien, el pensamiento crítico educativo (Morales, 2010).

Dadas estas múltiples voces y perspectivas, podemos encontrar una gran cantidad de versiones sobre cada uno de estos corpus teóricos; , por ello, con el fin de brindar un aporte al debate teórico educativo contemporáneo, y de llevar a cabo un intento de síntesis y de clarificación, la propuesta de este ensayo es reflexionar sobre el papel y el lugar que ocupa el pensamiento crítico en la teoría educativa contemporánea, sobre todo, en función de las dos derivaciones educativas que posee esta forma de razonamiento: la pedagogía crítica y la teoría crítica de la educación.

Para llevar a cabo este propósito, se realiza una exploración del concepto de pensamiento crítico así como del devenir que ha tenido esta concepción en algunas ramas de la Filosofía y de las Ciencias Sociales, con tal de entender, de la manera más precisa posible, de qué se trata el pensamiento crítico, cuáles son sus características y su modo de proceder en la reflexión.

Esta exploración sobre el pensamiento crítico permite evaluar las características de la pedagogía crítica y de la teoría crítica de la educación, con el fin de observar las principales tesis de ambas corrientes de pensamiento, los principales autores, las diferencias más importantes que existen entre ambas, y dar cuenta de hasta qué punto estas perspectivas son realmente tributarias del pensamiento crítico.

Posteriormente, se ensayan algunas críticas al pensamiento crítico y a sus variantes educativas, con el fin de contribuir a las discusiones contemporáneas sobre el lugar que ocupa el pensamiento crítico en la teoría educativa y el aporte que esta forma de razonamiento le brinda a la educación, tanto en aspectos teóricos como prácticos.

\section{La noción de pensamiento crítico}

En el mundo de la doxa, es decir, del lenguaje común, pensar críticamente es un tipo de razonamiento que podría ser definido de múltiples maneras, donde la mayoría tiene alguna 
relación con el acto de cuestionar o valorar, lo que resulta en el origen de la palabra crítica, cuya etimología procede del vocablo griego kpíoıs (kri), o sea, implica establecer un juicio o tomar una decisión. Por tal razón, cuando se habla de pensamiento crítico, en términos generales, se hace referencia a ejercicios de cuestionamiento y de valoración, que nos permitan finalmente emitir un juicio o tomar una posición con respecto a un hecho, a un fenómeno o a una idea.

Sobre el valor de la crítica hay distintas posiciones. Es posible encontrar valoraciones positivas sobre el pensamiento crítico, como una herramienta que es necesaria y que debe ser estimulada desde la educación y aplicada en la vida. También, es posible una posición contraria, que ha considerado como peyorativa la calificación de crítico, estableciéndolo como alguien que solo ve los aspectos negativos de un fenómeno, de una situación, un individuo o una acción (Morales, 2012).

En el campo intelectual, el término 'crítica' ha tenido una importancia notable en diversas disciplinas, pero son la Filosofía y las Ciencias Sociales dos espacios donde el pensamiento crítico ha encontrado un terreno fértil, y también donde los debates y cuestionamientos acerca de la función del pensamiento han sido más elaborados y recurrentes.

En el sentido filosófico moderno, la noción de crítica se le debe a Immanuel Kant (1724 -1804), considerado el fundador del pensamiento crítico en el razonamiento filosófico con tres de sus más importantes obras: Crítica de la razón pura (2002), Crítica de la razón práctica (2001) y Crítica del juicio (2000).

La importancia del sistema y del aporte filosófico de Kant se encuentra en el ámbito de la epistemología. La filosofía pre-kantiana intentó comprender de qué se trata el conocimiento humano, cuáles son sus procedimientos y qué instrumentos son los más aptos. Consistía esta filosofía en un intento por establecer la naturaleza y la mejor manera de producir el conocimiento humano.

Es por ello que la mayoría de filósofos pre-kantianos desarrollaron ensayos y tratados sobre el conocimiento. Francis Bacon (1561-1626) defiende el empirismo y prácticamente identifica el conocimiento humano con la experiencia, negando absolutamente todo conocimiento que no fuese alcanzado mediante métodos experimentales, y negando la posibilidad del conocimiento que estuviese sustentado en el puro razonamiento y no en la experiencia. Precisamente, la principal obra de Bacon es Novum organum: interpretación de 
la naturaleza y predominio del hombre (1933), un tratado sobre el lugar predominante de la técnica y de la experimentación como forma de conocer y dominar el mundo.

John Locke (1632-1704) va un paso más lejos que Bacon, y más que la experiencia concede el lugar al conocimiento solo en la percepción y no más que en ella. La percepción de las cosas sensibles es el único camino al conocimiento válido. Así, Locke restringe aún más el conocimiento que Bacon, pues quedan por fuera del mundo cognoscible aquellos objetos o datos de la realidad que no son sensibles, sino suprasensibles.

Básicamente, lo que no es perceptible es inexistente, aunque es claro que hoy sabemos de muchos datos de la realidad que no percibimos, pero que existen. La obra más conocida de Locke es su Ensayo sobre el conocimiento humano (1987), de nuevo un tratado pre-kantiano sobre el acto de conocer, en este caso remitido o entendido como experiencia y percepción.

Por su parte, George Berkeley (1685-1753) continúa con esta tradición de reflexiones sobre el conocimiento humano, al que consideró como ideas y representaciones mortales sobre las cosas sensibles. Para Berkeley solo hay seres que perciben y otros seres que son percibidos, las percepciones son ideas y representaciones, ergo, el conocimiento queda reducido a las ideas, las cuales provienen de Dios. La teoría de Berkeley es una defensa de la existencia de Dios mediante el desprecio a la experiencia pura y la exaltación de las ideas y de las representaciones. Dios es quien produce o crea los seres capaces de percibir y de ser percibidos. Berkeley escribe el Tratado sobre los principios del conocimiento humano publicado en 1710 (1994), continuando con la tradición de examinar qué significa conocimiento y qué significa el acto de conocer.

Después de Berkeley, la obra de David Hume (1711-1776) continúa con la tradición sobre el discernimiento de las facultades cognoscitivas humanas y el intento por descifrar el significado del acto de conocer. En Hume confluyen, sobre todo, el escepticismo y el positivismo. La duda razonable, la causalidad y la necesidad de una evidencia empírica constituyen, en su conjunto, un principio indispensable del conocimiento humano, en otras palabras, son los núcleos del pensamiento de Hume. Al respecto, en el pensamiento de Hume son notables las influencias de Locke y de Berkeley, por lo que su obra, dentro de la cual destacan, por ejemplo, Tratado de la naturaleza humana: ensayo para introducir el método del razonamiento experimental en los asuntos morales (1923), y su Investigación sobre el 
entendimiento humano publicada en 1748 (1994) siguen la tradición de los tratados elaborados por los filósofos pre-kantianos.

Estos cuatro ejemplos, Bacon, Locke, Berkeley y Hume, son casos sobresalientes de la tendencia en el pensamiento occidental que retomaba a la altura de los siglos XVII y XVIII, en medio de las luces de la llustración, temas sobre los cuales ya la filosofía occidental, desarrollada en Grecia y en el Asia Menor, había reflexionado anteriormente. Temas relacionados con la naturaleza del conocimiento y el significado de este acto, dentro de una epistemología que se pregunta por la manera óptima de construir el saber en distintos campos y disciplinas.

Mientras tanto, Kant hará algo diferente, introducirá una noción nueva, la idea de evaluar las condiciones de validez del conocimiento que se construye; por ello, su papel es considerado revolucionario en la historia del pensamiento, tanto que Arthur Schopenhauer (1960) se refiere a la obra de Kant como la causa de un verdadero renacimiento intelectual. Además de Schopenhauer, podríamos citar una gran cantidad de autores consagrados que expresan la importancia de la obra de Kant. Pero ¿en qué radica esa novedad de la filosofía kantiana, en qué su originalidad? Kuno Fischer (2002) menciona la distinción entre la filosofía de Kant y la filosofía anterior:

La filosofía pre-kantiana, sin pensar realmente en las condiciones del conocimiento, juzgaba sin recelo alguno la existencia de Dios, del mundo y de todas las cosas posibles; por eso era dogmática. En oposición a esta filosofía establece Kant la suya, que es crítica. La dogmática supone lo que debía ser investigado: la posibilidad de conocimiento; la crítica explica esta posibilidad. (p. 56)

La importancia de la filosofía kantiana está en que, por primera vez, se hace una evaluación epistemológica de las condiciones de validez del conocimiento, sin cuestionar la existencia 0 no de los fenómenos metafísicos, 0 de las impresiones sensibles 0 suprasensibles, o la utilidad de la experiencia. A diferencia de los filósofos anteriores, el objeto de estudio en Kant no es el conocimiento de los fenómenos, sino el proceso mismo de la razón.

Es por ello que sus obras no son grandes tratados o ensayos sobre el conocimiento humano, sino sobre la razón, sobre la estructura y los límites del método racional. Su crítica es epistemológica, porque cuestiona no el conocimiento, sino los límites de la razón y del 
entendimiento, no se cuestiona sobre los objetos, más bien cuestiona los límites, las condiciones y el nivel en que la razón puede acercarse a los objetos. Al respecto, en el prefacio a la primera edición de la Crítica de la razón pura (2002) Kant dicta: "la cuestión principal siempre sigue en pie, a saber: ¿qué es lo que entendimiento y razón, libres de toda experiencia, pueden conocer, y hasta donde pueden extender este conocimiento? $Y$ no: ¿Cómo es posible la propia facultad de pensar?” (p. 84).

Por esta diferencia con sus antecesores y con sus contemporáneos, podemos situar el origen del pensamiento crítico en la obra de Kant, cuyo objetivo era afinar, por medio de la crítica, el método del razonamiento filosófico, y objetivar la razón, la práctica y el juicio estético. Kant ve en la crítica de la razón el único medio por el cual el pensamiento y el conocimiento pueden refinarse y avanzar. La crítica de la razón, en palabras de Kant, es un tribunal ante el cual todo ha de someterse (2002, p. 82).

Es así como el pensamiento crítico nace siendo una crítica epistemológica, un examen de la razón y de sus métodos. Como crítica epistemológica indaga también las condiciones de validez en que el conocimiento es construido y, por lo tanto, la validez del conocimiento mismo. Después de Kant, vamos a encontrar una gran cantidad de tratados sobre crítica de la razón. De hecho, a partir de la triada kantiana, se abre un nuevo camino para el razonamiento, podríamos sostener que el pensamiento se vuelve sobre sí mismo y se evalúa a sí mismo.

Dentro de las elaboraciones posteriores una de las obras más destacadas del pensamiento crítico es la de Karl Marx (1818-1883). El trabajo de Marx coincide, además, con una época en la que las Ciencias Sociales ya se han distanciado, aunque no por completo, de la Filosofía y de la Filosofía Social, buscando ser reconocidas como ciencias en el ambiente académico e intelectual del siglo XIX. Como consecuencia, la obra de Marx es de transición, porque posee elementos de la Filosofía y aspiraciones científicas, ya en el campo de la Economía así como en el Derecho y la Sociología. El ámbito de influencia de Marx va a ser sumamente vasto, alcanzando casi todas las Ciencias Sociales y las Humanidades, para no hablar de su potente influencia en la política realista.

El marxismo es un esfuerzo intelectual por explicar el devenir de la sociedad tomando como punto de partida el materialismo y los distintos modos de producción y, además, el antagonismo de clase. Pero este esfuerzo intelectual no es solo un intento cientificista, sino que tiene aspiraciones prácticas. Estas aspiraciones están centradas en la idea de 
transformar el orden social y podemos verlas respaldadas en la muy famosa (citada y recitada una y otra vez) tesis número once de Marx sobre Feuerbach: Los filósofos no han hecho más que interpretar de diversos modos el mundo, pero de lo que se trata es de transformarlo (Marx, 1995).

El pensamiento de Marx es pensamiento crítico por dos razones: primero, es una forma de cuestionamiento de las maneras de proceder de la ciencia económica de su época, sobre todo de la economía política clásica desarrollada particularmente por autores británicos como David Ricardo (1772-1823) y Adam Smith (1723-1790). En las principales obras de Marx, tales como Contribución a la crítica de la economía política (1989), El Capital (1971), Manuscritos económico-filosóficos (1975), Sociología y filosofía social (1978), Manifiesto del Partido Comunista (1972), - escrito por Marx y Friedrich Engels-, es posible encontrar esa crítica a la razón económica y política burguesa, dominante en la época en que Marx escribió; por ello, Lenin consideraba que una de las fuentes del marxismo es precisamente la economía política clásica inglesa, pues Marx establece una crítica a esta forma de pensamiento (Lenin, 1973).

Segundo, el marxismo es pensamiento crítico, pues además de evaluar las condiciones de validez de la razón económica de su época, se convierte, también, en crítica social, en la medida en que denuncia y cuestiona realidades como la desigualdad social, la explotación de una clase sobre otra, la enajenación y alienación, así como el dominio ideológico que no es sino otra manifestación de la dominación de clase.

En esta operación del marxismo vemos puesta en práctica la citada tesis once sobre Feuerbach, donde Marx establecía como función de la Filosofía no solo la comprensión del mundo, sino su transformación. En cuanto a la comprensión el marxismo lo ha hecho muy bien, pues su aparato teórico y su engranaje metodológico son capaces de explicar la evolución de la sociedad desde el esclavismo hasta el capitalismo, y tocar a fondo las características de las sociedades capitalistas. Sin embargo, respecto a la transformación, las experiencias de socialismo real no son totalmente marxistas, sino que se han adecuado a condiciones histórico sociales, adaptándose a diferentes contextos, con niveles discutibles de éxito.

El trabajo de Marx es una forma de pensamiento crítico que además de ser epistémico, es social, pues no solo es una evaluación de las formas de conocimiento, y de los procedimientos de la razón en los terrenos de la Filosofía, la Economía, la Historia, el 
Derecho y la sociedad, sino que incluye una crítica y una visión de cambio sobre las condiciones sociales, sobre todo de aquellas condiciones de explotación y dominación, de forma que se convierte en crítica social.

Decía Loic Wacquant en una entrevista titulada Pensamiento crítico y disolución de la doxa, que desde su punto de vista el pensamiento crítico más fructífero es aquel en el que coinciden la crítica epistemológica kantiana, y la crítica social marxista (2006). Desde nuestro punto de vista, la afirmación de Wacquant es muy sugestiva; sin embargo, incompleta, pues debemos considerar la máxima de Pierre Bourdieu (2000) que dicta, las armas de la crítica, deben ser científicas para ser efectivas. En consecuencia, el pensamiento crítico que tome en cuenta la cuestión social, debe ser no solo crítica desde el sentido común, sino que debe ser científico social, con el fin de que sea efectivo. Al decir científico social, Bourdieu plantea que el conocimiento se debe desarrollar en el marco de la problematización teórica y la confrontación empírica, solo el conocimiento que cumpla con estas dos condiciones podría ser considerado como pensamiento crítico. Además, P. Bourdieu (2000) dirá que antes de pensar cómo nos gustaría que fuese la realidad, debemos primero comprender cómo es, hasta ese momento estaremos facultados para pensar en otras posibilidades.

En este punto podemos entonces definir el pensamiento crítico como una forma de razonamiento que combina el análisis epistemológico y científico social, con la finalidad de comprender la realidad y, además, cuestionar nuestra forma de comprenderla, nuestro aparato teórico y metodológico que nos sirve para el análisis de la realidad social, para finalmente pensar en posibilidades de acción sobre la realidad estudiada. Nótese que para llegar a esta definición es necesario tener claro el sentido de la concepción de crítica kantiana y marxista, así como el aporte de Pierre Bourdieu y Loic Wacquant en torno al pensamiento crítico (Morales, 2012).

Después de Kant y de Marx, han aparecido una gran cantidad de trabajos sobre crítica de la razón o, para precisar más, sobre distintos tipos de razonamiento. Sin ser exhaustivos, podríamos citar a modo de ejemplos: Crítica de la razón instrumental de Horkheimer (1969), Crítica de la razón dialéctica de J.P. Sartre (1963), Crítica da razão indolente de Boaventura de Sousa (2002), Critique of Cynical Reason, de Peter Sloterdijk, Crítica a la razón utópica, de Franz Hinkelammert (1984). Y aunque podríamos citar muchos ejemplos más de este tipo de tratados, de igual forma se nos escaparán una gran cantidad. 
De manera que el pensamiento crítico, o la crítica de distintos tipos de razonamiento, ha sido común a partir de Kant y de Marx, y a pesar de que, desde el punto de vista bourdesiano, el pensamiento crítico debe ser científico para ser efectivo, esta forma de razonamiento no es solo científica, filosófica o académica. Hay pensamiento crítico en algunas formas de arte, música o literatura, donde también podríamos citar una gran cantidad de ejemplos, sin agotar nunca la totalidad de manifestaciones de pensamiento crítico existente.

Un lugar donde el pensamiento crítico ha tenido influencia notable es en la Educación. Esta influencia ha sido desarrollada de múltiples maneras, pero para concretar y focalizar el análisis, el siguiente apartado se centra específicamente en dos de las derivaciones más comunes e importantes del pensamiento crítico en la educación: la teoría crítica de la educación y la pedagogía crítica.

\section{Teoría crítica de la educación y pedagogía crítica: formas de pensamiento crítico}

Aunque los términos teoría crítica de la educación y pedagogía crítica se encuentran muy próximos, resulta fundamental establecer una mayor precisión conceptual en su uso, con el fin de definir, de una manera más clara, a qué se refiere cada uno de esos términos. Incluso, algunos autores suelen usarlos, indistinta o equívocamente, sobre todo, pensando o sugiriendo qué tanto la pedagogía crítica como la teoría crítica de la educación provienen de la teoría crítica de la Escuela de Frankfurt, cuando, en realidad, como se ensayará más adelante, solo la teoría crítica de la Educación es una derivación directa de Frankfurt y sus teóricos. Por ejemplo, Ana Maestre (2009) indica: "La pedagogía critica extrae la tesis de Adorno, Benjamín y Marcuse acerca de cómo a través de la cultura la conciencia sobre el lenguaje se podría orientar a la humanidad hacia una praxis dela intersubjetividad, mediante una acción pedagógica" (p. 2).

En realidad, la pedagogía crítica no extrae estas ideas directamente de los teóricos de la Escuela de Frankfurt, sino que su principal fundamentación es una lectura de Karl Marx (1818-1883) y de Antonio Grammsci (1891-1937), y su propuesta es mucho más práctica que teórica, a diferencia de la teoría crítica de la educación, cuyo principal objetivo es precisamente teorizar, desde una forma de pensamiento crítico, el fenómeno educativo.

Además, hay otros autores que utilizan categorías conceptuales del marxismo para estudiar la educación, y que no califican dentro de la pedagogía crítica ni dentro de la teoría 
crítica de la educación, sino que se agrupan dentro del análisis marxista de la educación, tal como lo habíamos mostrado en otro artículo (Morales, 2009a).

Entonces, para alcanzar mayor exactitud conceptual, podemos definir la teoría crítica de la educación como reflexiones y razonamientos teórico-educativos, que toman los conceptos y los análisis de la teoría crítica elaborada por la Escuela de Frankfurt, con tal de entender, comprender y explicar distintos aspectos de la educación como fenómeno social.

Mientras la teoría crítica de la educación tiene un enfoque más académico, más cientificista, la pedagogía crítica tiene un carácter menos explicativo y más orientado hacia la práctica, o si se prefiere, hacia la praxis, término predilecto de los pedagogos críticos. La idea de la pedagogía crítica es realizar un trabajo educativo basado en el diálogo (por ello, es dialéctica), que le permita a los individuos tomar conciencia de las condiciones de opresión que pueden existir, con el fin de puedan iniciar la construcción de una nueva realidad, donde no exista la dominación ni la desigualdad.

Puede existir cierto consenso en que el fundador de lo que hoy conocemos como pedagogía crítica fue Paulo Freire (1921-1997). A pesar de ese cierto consenso podríamos encontrar algunas voces disidentes, pero como cualquier tema, sobre todo en cuestiones de establecer orígenes, es esperable la discusión. Aunque Paulo Freire no se calificó a sí mismo como pedagogo crítico, son otros los que sostienen que fue el fundador de esta corriente. Esa idea tiene su origen en el análisis de la obra de Freire y de las acciones educativas que llevó a cabo. Por ejemplo, Richard Colwell (2005) sostiene que Freire es usualmente considerado como el primero: Freire is often cited as the primary exponent of critical pedagogy ${ }^{2}$ (p.6).

También, a pesar de ese consenso que le otorga a Freire el título de pionero, no ha sido Freire, quien más ha hablado de pedagogía crítica. En sus principales obras, como Pedagogía del oprimido (1975), La educación como práctica de libertad (1978), Política y educación (1998), Pedagogía de la esperanza (1999) Pedagogía de la autonomía: saberes necesarios para la práctica educativa (2002b), o en las Cartas a quien pretende enseñar (2002a), no utiliza el concepto de pedagogía crítica.

Tampoco cita en esas obras a teóricos de la escuela de Frankfurt, con excepción de Herbert Marcuse (1898-1979), cuyos textos el Hombre unidimensional (1971) y Eros y civilización (1969) son citados una vez en la Pedagogía del oprimido (1975) y mencionado,

\footnotetext{
${ }^{2}$ Freire es a menudo citado como el primer exponente de la pedagogía crítica (traducción propia).
} 
algunas veces, en Pedagogía de la esperanza (1999). En cambio, sí son recurrentes en las obras de Freire, evocaciones a Karl Marx (1818-1883), o bien, a Georg Lukács (1885 -1971), también un teórico marxista.

Entre todos los libros citados de Paulo Freire, tampoco utiliza el término pedagogía crítica, una de las pocas ocasiones en que menciona este término es en el seminario-taller llamado Práctica de la pedagogía crítica, que forma parte de los documentos agrupados en la obra titulada El grito manso (2003), que recoge seminarios y conferencias brindadas por el autor. En ese seminario-taller Freire menciona lo siguiente:

Les he dicho que una de las tareas fundamentales, tanto aquí en Brasil y en el mundo entero es elaborar una pedagogía crítica. Y se los digo, no como alguien que ya fue, se los digo como alguien que está siendo. Igual que toda la gente yo también estoy siendo, a pesar de la edad. En función y en respuesta a nuestra propia condición humana, como seres conscientes, curiosos y críticos, la práctica del educador, de la educadora, consiste en luchar por una pedagogía critica que nos de instrumentos para asumirnos como sujetos de la historia. Practica que deberá basarse en la solidaridad. (p. 30)

Así queda claro que para Freire la pedagogía crítica no es aun una corriente acabada, es necesario construirla. A Paulo Freire se le ha considerado un pedagogo crítico no por definir y aplicar algo que tenga como nombre pedagogía crítica, sino por desarrollar una tendencia educativa que se basa principalmente en la práctica y en el cuestionamiento de la realidad social capitalista, la cual se funda en la desigualdad de clase.

El método de alfabetización de Paulo Freire, aplicado sobre todo en sectores económica y socialmente desfavorecidos de la sociedad brasileña, no es solamente una forma de aprender a leer y escribir, sino que tiene como fundamento la idea de que ese capital cultural es necesario para desarrollar la conciencia de clase y que la concientización de las clases explotadas conduce a la lucha por su liberación.

Una exposición del pensamiento de Freire, en términos de su ideal de acción liberadora, se encuentra desarrollada en el trabajo doctoral de Oscar Fernández titulado Paulo Freire ou les conditions d'une action culturelle liberatrice (1979), en el cual se analizan los núcleos más sobresalientes de la concepción educativa de este autor, desde el punto de vista de su concepción de la praxis educativa como acción social emancipadora. 
El eje de la pedagogía crítica es la concepción de educación como praxis que permite alcanzar la emancipación de las clases oprimidas por medio de la concientización que se logra realizando un cuestionamiento de la realidad social inmediata. En este caso, se podría plantear la idea de que "la verdad también nos hará libres", siempre y cuando esa verdad sea alcanzable a través de procesos educativos que acerquen los temas de estudio a la realidad inmediata de los discentes, y les permitan comprender su realidad para transformarla, he aquí el ligamen con el marxismo.

La teoría crítica de la educación, en cambio, no necesariamente posee un carácter práctico, puede tenerlo, pero también puede prescindir de ese carácter, tal como lo han hecho muchos de sus autores, la mayoría precisamente teóricos de la educación más que prácticos de la educación, aunque en muchos de sus textos hablen de praxis educativa.

Esta tendencia es sobre todo europea y estadounidense. Aunque existen algunos teóricos críticos de la educación en el subcontinente latinoamericano, y probablemente en otras regiones del mundo, su origen está en Europa, por la influencia directa que tuvieron los intelectuales de la Escuela de Frankfurt en el pensamiento educativo europeo y luego en el estadounidense, debido al exilio que algunos de estos teóricos durante la Segunda Guerra Mundial.

Esta corriente de pensamiento posee influencias diversas, desde el neo marxismo, la Escuela de Frankfurt (la cual es la influencia más notable), algunas ideas de Paulo Freire, (sobre todo, en Henri Giroux), e incluso algunos teóricos estructuralistas como Pierre Bourdieu y Jean Claude Passeron (Morales, 2010).

Dentro de los principales representantes de la teoría crítica de la educación sobresalen los autores Wilfred Carr, Stephen Kemmis, Basil Bernstein, Peter MacLaren, Michael Apple, y Henri Giroux. El aporte de la teoría crítica de la educación ha estado centrado en la reflexión sobre temas tales como la validez de las teorías reproduccioncitas ${ }^{3}$ de origen bourdesiano (Morales, 2009b), el análisis de la desigualdad escolar, trabajos sobre teoría curricular (Kemmis y Fitzclarence, 2008), análisis ideológico, cultura política (McLaren, 2000),

\footnotetext{
${ }^{3}$ Las teorías de la reproducción tienen su punto alto de desarrollo, sobre todo, con el trabajo que Pierre Bourdieu realizó sobre la educación, el cual se ha convertido en un paradigma de la sociología de la educación, incluso la llama una "teoría total", pues explica el funcionamiento del sistema educativo y, además, explica las evidencias que podrían contradecir la teoría. La educación y, particularmente, el sistema de enseñanza es para Bourdieu un mecanismo de reproducción de la desigual distribución del capital cultural, que colabora, a su vez, con la reproducción en la desigualdad social y económica. En efecto, es este concepto de capital cultural el elemento novedoso en la teoría bourdesiana, porqueen las elaboraciones sociológicas anteriores la educación se concebía siempre relacionada al capital económico, pero no al capital cultural.
} 
democratización de la escuela y de la enseñanza (Carr y Kemmis, 1988), y el lugar de la teoría crítica en el debate educativo (Apple, 1997; Giroux, 2006), entre muchas otras temáticas, pero son las anteriores las más sobresalientes.

A diferencia de la pedagogía crítica, no podemos establecer un solo tema o punto como fundamental dentro de la teoría crítica de la educación, ya que existe una variedad considerable de temáticas, tal como lo apuntamos en el párrafo anterior. Sin embargo, sí es posible establecer los núcleos más importantes de la propuesta de esta corriente de pensamiento. Al menos podemos hablar de cinco núcleos de análisis en los que se sustenta la teoría crítica de la educación:

1. El primero de estos tiene que ver con la idea de que la educación debe ser llevada a cabo por docentes que asuman el papel de intelectuales reflexivos, transformadores, y pendientes de los problemas sociales de la Escuela. Esto ha llevado a algunos teóricos como Wilfred Carr y Stephen Kemmis, a defender la investigación-acción como una forma mediante la cual los docentes puedan llevar a cabo procesos reflexivos e investigativos desde y para el aula (Carr y Kemmis, 1988). Para ellos lo fundamental es que los docentes tomen conciencia sobre los problemas que enfrentan día a día en su trabajo docente, y puedan transformar la enseñanza con el fin de mejorar los procesos educativos.

2. El segundo está relacionado con el tema de la desigualdad social, la explotación y la iniquidad, estableciendo una crítica al sistema capitalista y a la función de la institución escolar dentro de este sistema. Desde esta perspectiva, la educación institucionalizada funciona como un elemento de reproducción social, ubicando a los individuos en una parte determinada de la estructura social. Este proceso es potenciado por el control, el discurso educativo, y el currículum oculto que está presente en la práctica escolar (Bernstein, 1977; 2001). En esta forma de análisis lo importante es comprender el funcionamiento de la escuela como mecanismo de reproducción social, con tal de poder idear las maneras de incidir en este proceso de manera positiva.

3. En tercer lugar, el tema de la democratización de los procesos educativos y de la institución escolar es otra constante en la teoría crítica de la educación. Por lo general, estos teóricos llegan a la conclusión de que la manera en que la institución escolar está pensada y funciona, es fundamentalmente un planteamiento autoritario, donde las decisiones son tomadas arbitraria y verticalmente (Giroux, 2006; McLaren, 1998). La 
idea es entonces democratizar la escuela y los procesos educativos, con tal de que los estudiantes sean considerados como gestores del aprendizaje, y sean tomados en cuenta en las decisiones (Giroux y McLaren, 1998). Esto, según los teóricos críticos de la educación, permitirá que los estudiantes se formen positivamente en la participación política para que se vinculen como ciudadanos en procesos de toma de decisiones mayores, relacionados con la vida política fuera de la escuela (Apple, 1999).

4. El cuarto punto de análisis tiene que ver con los procesos de comunicación en la actividad educativa. Esta perspectiva comunicativa, tal como la llama Ana Ayuste, Ramón Flecha, Fernando López y Jordi Lleras (1999), es una influencia directa de Jurgen Habermas, miembro de la Escuela de Frankfurt, y su teoría de la acción comunicativa (Habermas, 2001; 1982). En concreto, la idea es que mediante el diálogo, y la evaluación de las categorías discursivas de los sujetos, así como de la autorreflexión, es posible alcanzar consenso, que se da cuando las condiciones de los actos del habla son democráticas, de manera que todos los participantes detengan la posibilidad de plantear sus diferentes puntos de vista. El consenso es un estado clave que permite tomar acuerdos sobre las acciones posibles, las cuales deben estar orientadas a la transformación de las condiciones sociales de existencia.

5. Finalmente, el punto número cinco tiene que ver con el concepto de emancipación, central en la teoría crítica de la educación, pues para todos estos teóricos, se trata de un estado ideal en el que los individuos, por medio del diálogo, la reflexión y la crítica, pueden tomar conciencia sobre sus condiciones sociales, y emanciparse de ellas. Este concepto es transversal a todas las obras de teoría crítica de la educación y es, desde este punto de vista teórico, la función última que debe cumplir la escuela. El concepto es definido por Habermas de la siguiente manera: Emancipación significa independencia de todo lo que esta fuera del individuo (1982, p. 253). En la teoría crítica de la educación, esta influencia de Habermas va a estar presente, y el concepto de emancipación se convierte en la consigna de esta propuesta teórica.

Estos son los núcleos analíticos de la teoría crítica de la educación. Desde esas concepciones, que sirven como engranaje teórico conceptual, esta corriente teórica aborda variados temas en contextos sumamente diferenciados, y desde una amplitud de puntos de vista, con el fin de dar cuenta sobre el papel de la educación en la sociedad. 
Como se ha mostrado, la pedagogía crítica se diferencia en mucho de la teoría crítica de la educación, aunque podríamos tener en cuenta algunas semejanzas, como el hecho de que ambas corrientes de pensamiento provienen del marxismo y ambas son formas de pensamiento crítico, aunque no del todo epistemológico, sino más bien se trata de un tipo de crítica científico social y teórico-empirista, fiel a su origen marxista.

\section{Críticas al pensamiento y la educación crítica}

Kant había planteado en la Crítica de la razón pura (2002) que su época era la de la crítica, y que a la crítica todo debe someterse, desde la Iglesia hasta la legislación, y también a la crítica debe ser sometido el pensamiento crítico así como su derivación educativa. En este apartado proponemos cinco críticas fundamentales a estas formas de razonamiento.

La primera crítica está relacionada con el concepto de emancipación, que es común tanto al pensamiento crítico como a la educación crítica. Tal como lo habíamos citado, el concepto de emancipación proviene de Habermas (1982), y básicamente lo entiende como un estado de independencia individual con respecto al mundo exterior. Este concepto implica entonces una ruptura del individuo con su entorno y, además, trae consigo el concepto de libertad. De hecho, el concepto de emancipación constituye un acto de liberación, de acceso a la libertad.

El problema es que desde la ciencia social, esta noción de ruptura con respecto al mundo externo, y la libertad individual no es concebible. Pierre Bourdieu había señalado en la obra Cuestiones de sociología (2000), que lo individual, tal como suele suponerse, no es una oposición a lo social, sino que, por el contrario, lo individual es una de las formas de existencia de lo social, pues es la sociedad la que deposita en las conciencias individuales, distintas formas de hacer, de pensar y de obrar. Este proceso de interiorización no es del todo consciente, de manera que los individuos pueden suponer que toman sus decisiones utilizando una especie de libre albedrío, cuando, en realidad, sus decisiones están condicionadas y, a veces, determinadas socialmente.

También, Michel Foucault, en El sujeto y el poder (1988), sostiene que la definición de sujeto debe entenderse como individuo atado o sometido, tanto a los otros, por relaciones de dependencia, control y dominación, como a sí mismo, por su propia identidad y la imagen que posee de sí mismo. Y, además, si consideramos esta idea de Foucault complementada con el 
planteamiento bourdesiano, cuando Foucault dice sometido a sí mismo, está diciendo de nuevo sometido a lo social, porque lo social se manifiesta en lo individual.

De modo que el concepto de emancipación termina siendo una consigna demasiado idealista tanto del pensamiento como de la educación crítica. En efecto, el ser humano no puede ser absolutamente libre y autónomo, sino que está en todo momento sometido a estructuras de relaciones de poder, por lo que tal y como la plantean las corrientes críticas, la emancipación es teórica y prácticamente imposible de concretarse.

La segunda crítica se centra en el uso excesivo del concepto de praxis. La interpretación de la tesis once de Marx sobre Feuerbach (1995) puede llevarse al extremo de creer que no es necesario teorizar o comprender y que debido a la sugerencia de Marx relacionada con transformar el mundo, lo que necesitamos es actuar, de ahí el abuso en el tema de la praxis. Sobre el tema, Slavoj Zizek ha sugerido la necesidad de invertir, en nuestra época, la tesis once, y volver a pensar y a comprender antes de actuar y llegar al extremo del activismo irracional. Dice Zizek (2007):

I am deeply suspicious of this pseudo-sense of urgency. I think it is the same as "act, so that you don't have to think." Today, more than ever, we need time to think. This does not mean that we do not protest or do what is possible. But let's not behave as if everything is clear. I do not think we even have a convincing theory of where are we today ${ }^{4}$.

El acto de teorizar también es imprescindible, tal como lo sugiere Zizek, el exceso en la praxis puede llevar al extremo del activismo sin una teoría que permita orientar las acciones de los individuos. Esta es la causa por la que muchas protestas y acciones terminan con el fin de la protesta misma, sin mayores implicaciones futuras.

Es este un punto débil del pensamiento crítico, sobre todo en educación, pues se le ha dado un papel demasiado preponderante a la práctica, relegando el propio pensamiento a un segundo plano. Nótese que tal como la habíamos sugerido, mucho del pensamiento crítico educativo está mayormente influenciado por la noción de praxis en el marxismo, de origen crítico-social, pero hay muy poco de influencia kantiana y de crítica epistemológica.

\footnotetext{
${ }^{4}$ Sospecho profundamente de ese pseudo sentido de urgencia. Creo que es lo mismo que decir "actúa de manera que no es necesario pensar". Hoy más que nunca necesitamos tiempo para pensar. Esto no significa que no debemos protestar o hacer lo que sea posible. Pero no nos comportemos como si todo está claro. No creo que tengamos ni siquiera una teoría realmente convincente de donde estamos hoy (traducción propia).
} 
La tercera crítica tiene que ver con el concepto de democratización, sobre el cual se insiste en el pensamiento crítico educativo. Como vimos, hay un planteamiento muy pertinaz en el tema de democratizar la escuela y los procesos educativos. Cuando en realidad la idea de democracia es muy difusa, no se define de qué tipo de democracia se está hablando, tampoco se tienen claros los procedimientos democráticos que se utilizarían, de manera que cualquier forma de decisión colectiva sobre algún asunto es considerada democracia. Hay dos ideas iguales en ambos párrafos.

La carencia de una definición mínima de democracia debilita el pensamiento crítico educativo, pues no se tiene claro de qué se está hablando cuando se habla de democracia. La democracia es un sistema que posee un conjunto de reglas aceptadas, y que permiten definir quienes acceden al poder. Si se trata simplemente de tomar el criterio de los individuos participantes en los procesos educativos, con tal de tomar decisiones específicas, estamos en presencia de un sistema de igualdad, más que de un sistema democrático.

Por otro lado, tal como lo señala Norberto Bobbio (1985), la democracia es una invención liberal, es la ideología política del sistema capitalista, y tiene limitaciones, o lo que Bobbio llama promesas incumplidas, siendo una de estas promesas rotas, la educación de la ciudadanía. Entonces, ¿por qué una corriente crítica, de orientación marxista, incurre también en la idealización de la democracia al punto de llevarla al salón de clase? Esto ocurre por una inconsistencia del pensamiento crítico educativo y la falta de creatividad necesaria para pensar en formas alternativas de vida social

La cuarta crítica es la que considera al pensamiento crítico y a la educación crítica como un funcionalismo inverso (Criado, 2003). El punto es que el pensamiento crítico educativo nace como una alternativa al funcionalismo de Durkheim y Parsons (Morales, 2010) y al sistema educativo capitalista que se basa en la formación de ciudadanos útiles al sistema, integrados a su sociedad y respetuosos del orden.

Sin embargo, el problema consiste en que el pensamiento crítico educativo se convierte también en una forma de funcionalismo, pero inverso, en el cual los individuos deben ser educados para funcionar en otro sistema, y deben ser útiles para otros fines, que se consideran discursivamente más nobles y dignos, y como fines verdaderamente importantes.

En ambos casos, así como lo señala Martín Criado (2003), tanto en el funcionalismo como en el pensamiento crítico educativo, existe una ideología, existe legitimación, y si lo complementamos con Pierre Bourdieu, existe también violencia simbólica, entendida como 
una acción pedagógica que selecciona e inculca una arbitrariedad cultural, mediante una relación comunicativa, y haciendo uso de la autoridad pedagógica (Bourdieu y Passeron, 1996). Toda acción pedagógica, aunque sea crítica, es una acción de violencia simbólica.

Finalmente, la quinta crítica es que el pensamiento crítico, así como la educación crítica corren el riesgo de convertirse en una forma de dogmatismo. El pensamiento dogmático es irreflexivo y toma las realidades por dadas. Si el pensamiento crítico no se cuestiona a sí mismo, estamos en presencia de un pensamiento sectario y dogmático. $Y$, en efecto, existen manifestaciones del pensamiento crítico educativo que tienen un carácter dogmático y maniqueo de la realidad social.

Cuando el pensamiento crítico se propone como la única alternativa válida para salir de la dominación que se lleva a cabo mediante el sistema capitalista y la institución educativa, no solo trata de imponerse sobre las conciencias individuales, sino que se autopresenta como la verdad ante un mundo de falsedades. El pensamiento crítico, para ser verdaderamente aceptado como tal, debe ser crítico de sí mismo, y combinando tanto la crítica epistemológica kantiana como la crítica científico social marxista.

\section{Consideraciones finales}

A modo de conclusión, es pertinente plantear una pregunta más que dar respuestas, esta pregunta es la siguiente: ¿Cuál es el papel de la teoría crítica y de la pedagogía crítica en la teoría educativa contemporánea? Teniendo en cuenta las definiciones aportadas para el pensamiento, la pedagogía y la teoría crítica de la educación, así como sus principales temas, problemas, conceptos, autores, y críticas, es posible ensayar una valoración sobre el lugar que estas formas de razonamiento ocupan en el debate actual.

La respuesta puede ser muy similar a la que da Loic Wacquant (2006), cuando se le pregunta por la influencia del pensamiento crítico en la actualidad, y sin ser contradictorio apunta que es, al mismo tiempo, extremadamente fuerte y terriblemente débil (p.45), pues contamos con una aparato teórico y con evidencias empíricas contundentes sobre el funcionamiento de la desigualdad, de la explotación de la dominación en todas sus formas, y en diversos espacios, siendo el campo educativo un lugar privilegiado por la cantidad de investigaciones que se han realizado sobre la educación desde la perspectiva crítica.

El desarrollo de investigaciones sobre el funcionamiento de los mecanismos de poder en espacios como el trabajo, la economía, la sexualidad y el género, la escuela, entre muchos 
otros, es exhaustivo y extenso, pero de igual manera, esas realidades que comprendemos teórica y empíricamente, persisten a pensar de nuestra comprensión del mundo social. Y esto ocurre con particular fuerza en el campo de la educación y en el ámbito de las relaciones y fenómenos que se dan dentro de ese campo.

El papel de la teoría crítica de la educación y de la pedagogía crítica ha sido y sigue siendo fundamental, tanto como tema de estudio así como herramienta de trabajo. Probablemente, Paulo Freire es uno de los autores más leídos en las facultades de Educación y de Ciencias Sociales del mundo, no solo en el de habla portuguesa e hispanohablante, sino también en otros espacios como el estadounidense.

La influencia de la educación crítica es muy fuerte en los espacios académicos, y se podrían citar una gran cantidad de investigaciones que enarbolan las banderas de la crítica, pero en el mundo social cotidiano, la dominación, la exclusión y la explotación siguen funcionando.

Asimismo, vale la pena reflexionar sobre las críticas que se le pueden plantear a la educación crítica, por ejemplo, las que hemos propuesto en este ensayo pues resolver esos problemas fortalecería eventualmente a esta forma de pensamiento.

La educación crítica actual ocupa un lugar preponderante en la teoría educativa contemporánea, y probablemente lo siga ocupando por mucho tiempo más, pues los debates que propone tienen vigencia y lo problemas que aborda no se van a resolver pronto; además, proporciona teorías y evidencias empíricas que permiten entender el funcionamiento de la educación.

De modo que podemos concluir que en la teoría contemporánea de la educación, el pensamiento crítico tiene una gran vigencia, el problema sigue siendo cómo darle vigencia no solo en la teoría, sino en la práctica educativa, tema que podría ser abordado en otros trabajos. La aplicabilidad de la teoría y de la pedagogía crítica puede desarrollarse al menos en dos vías, una es el propio trabajo de aula, esto es, utilizar los componentes y constructos teóricos en el trabajo docente, aplicándolo a la enseñanza de las distintas disciplinas que conforman los currícula. Una segunda vía es la utilización de esta teoría como un marco analítico y teórico explicativo aplicable en los procesos de investigación didáctica, pedagógica y socioeducativa en general. Concretar esta aplicación continúa siendo el reto actual de la pedagogía crítica y de la teoría crítica de la educación. 


\section{Referencias}

Apple, Michael. (1997). Teoría crítica y educación (Serie educación internacional). Buenos Aires Miño y Dávila Editores.

Apple, Michael. (1999). Escuelas democráticas (3a. ed.). Morata Colección pedagogía. La pedagogía hoy. Madrid.

Ayuste, Ana, Flecha, Ramón, López, Fernando y Lleras, Jordi. (1999). Planteamientos de la pedagogía critica. Comunicar y transformar. $3^{\circ}$ Ed. Madrid: Editorial Grao.

Bacon, Francis. (1933). Novum organum: interpretación de la naturaleza y predominio del hombre. Madrid: Editorial Espasa-Calpe.

Bernstein, Basil. (1977). Class, Codes and Control (Vol. 3, Towards a Theory of educational transmissions). London: R.K.P

Bernstein, Basil. (2001). La estructura del discurso pedagógico (4a. ed.). Madrid: Morata Colección pedagogía. Educación crítica.

Berkeley, George. (1994). Tratado sobre los principios del conocimiento humano (Grandes obras del pensamiento $\left.\mathrm{N}^{\circ} 35\right)$. Barcelona: Editorial Altaya.

Bobbio, Norberto. (1985). El futuro de la democracia. Barcelona: Plaza y Janés.

Bourdieu, Pierre y Passeron, Jean Claude. (1996). La Reproducción: elementos para una teoría del sistema educativo. México: Fontamara.

Bourdieu, Pierre. (2000). Cuestiones de sociología. Madrid: Editorial Istmo.

Carr, Wilfred y Kemmis, Stephen. (1988). Teoría crítica de la enseñanza: la investigaciónacción en la formación del profesorado. Barcelona: Martínez-Roca.

Colwell, Richard. (2005). Taking the temperature of critical pedagogy. Visions of Research in Music Education, 6. University of Illinois. Recuperado de http://wwwusr.rider.edu/ vrme/v6n1/visions/Colwell\%20Taking\%20the\%20Temperature\%20of\%20 Critical\%20Pedagogy.pdf

Criado, Martin. (2003). Una crítica de la sociología de la educación critica. Anduli, Revista Andaluza de Ciencias Sociales, (2), 9-27. Universidad de Sevilla. España

Fischer, Kuno. (2002). Historia de los orígenes de la filosofía crítica. En Immanuel Kant. Crítica de la razón pura (Traducción de J. Rovira Armengol). Barcelona: Ediciones Folio.

Fernández González, Oscar. (1979). Paulo Freires ou les conditions d'une action culturelle liberatrice. (Tesis Doctoral). Universite de Paris X, Nanterre, París, Francia.

Foucault, Michel. (1988). El sujeto y el poder. Revista mexicana de Sociología, 50(3), 3-20. 
Freire, Paulo. (1975). Pedagogía del oprimido (16a. ed.). México: Siglo Veintiuno Editores.

Freire, Paulo. (1978). La educación como práctica de la libertad (22a. ed.). México: Siglo Veintiuno Editores.

Freire, Paulo. (1998). Política y educación. 3. edición. Siglo Veintiuno Editores. México.

Freire, Paulo. (1999). Pedagogía de la esperanza: un reencuentro con la pedagogía del oprimido (4a. ed.). México: Siglo Veintiuno Editores.

Freire, Paulo. (2002a). Cartas a quien pretende enseñar (8a. ed.). México: Siglo Veintiuno Editores.

Freire, Paulo. (2002b). Pedagogía de la autonomía: saberes necesarios para la práctica educativa (2a. ed.). Argentina: Siglo Veintiuno Editores.

Freire, Paulo. (2003). El grito manso (Educación General № 13). Buenos Aires, Argentina: Siglo Veintiuno.

Giroux, Henri y McLaren, Peter. (1998). Sociedad, cultura y educación (Serie educación internacional). Madrid: Miño y Dávila.

Giroux, Henri. (2006). La escuela y la lucha por la ciudadanía: pedagogía crítica de la época moderna (4a. ed.). México, D.F.: Siglo Veintiuno Editor.

Habermas, Jurgen. (1982). Conocimiento e interés. Madrid: Taurus Ediciones.

Habermas, Jurgen. (2001). Acción comunicativa y razón sin trascendencia. Barcelona: Editorial Paidos.

Hume, David. (1923). Tratado de la naturaleza humana: ensayo para introducir el método del razonamiento experimental en los asuntos morales. Madrid: Editorial Calpe.

Hume, David. (1994). Investigación sobre el entendimiento humano. México: Editorial Gernika.

Kant, Immanuel. (2000). Crítica del juicio. México D.F.: Editores Mexicanos Unidos.

Kant, Immanuel. (2001). Crítica de la razón práctica (Traducción de Antonio Zozaya). Madrid: Ediciones Mestas.

Kant, Immanuel. (2002). Crítica de la razón pura (Traducción de J. Rovira Armengol). Barcelona: Ediciones Folio.

Kemmis, Stephen y Fitzclarence, Lindsay. (2008). El curriculum: más allá de la teoría de la reproducción (4a. ed.). Madrid: Morata. Colección pedagogía. La pedagogía hoy.

Lenin, Vladimir. (1973). Tres fuentes y tres partes integrantes del marxismo (3a. ed.). Buenos Aires: Editorial Anteo. 
Locke, John. (1987). Ensayo sobre el entendimiento humano (Compendio). Madrid: El libro Aguilar.

Maestre, Ana. (2009). Reflexión sobre la pedagogía crítica. Revista Digital Innovación y Experiencias Educativas, (14), 1-16. Recuperado de http://www.csicsif.es/andalucia/modules/mod ense/revista/pdf/Numero 14/ANA\%20BELEN MAESTR E 2.pdf

Marcuse, Herbert. (1969). Eros y civilización. Barcelona: Biblioteca breve de bolsillo, Libros de enlace 54.

Marcuse, Herbert. (1971). El hombre unidimensional: ensayo sobre la ideología de la sociedad industrial avanzada (6a. ed.). Barcelona: Biblioteca breve de bolsillo 24.

Marx, Karl. (1955). Tesis sobre Feuerbach. En: Obras Escogidas de Marx y Engels Tomos I y II. Moscú: Editorial MIR.

Marx, Karl. (1971). El capital. Editora Nacional (Colección económica). México: Libros de bolsillo.

Marx, Karl y Engels, Friedrich. (1972). Manifiesto del Partido Comunista. Moscú: Editorial Progreso.

Marx, Karl. Engels, F. (1975). Manuscritos económico-filosóficos de 1844. México: Editorial Grijalbo.

Marx, Karl. (1978). Sociología y Filosofía social (Selección de textos e introducción de T. Bottomore). Barcelona: Editorial Península.

Marx, Karl. (1989). Contribución a la crítica de la economía política. México: Editorial Progreso.

McLaren, Peter. (2000). Pedagogía crítica, resistencia cultural y la producción del deseo (2a. ed., Colección cuadernos 5). Buenos Aires: Aique.

McLaren, Peter. (1998). Multiculturalismo revolucionario: pedagogías de disensión para el nuevo milenio. México: Siglo Veintiuno Editores.

Morales Zúñiga, Luis Carlos. (2009a). Educación y sociedad: apuntes para una aproximación a la praxis educativa desde el marxismo. Revista Actualidades Investigativas en Educación. Instituto de Investigación en Educación, 9(2), UCR. Recuperado de http://revista.inie.ucr.ac.cr/ediciones/controlador/Article/accion/show/articulo/educaciony-sociedad-apuntes-para-una-aproximacion-a-la-praxis-educativa-desde-elmarxismo.html

Morales Zúñiga, Luis Carlos. (2009b). Durkheim y Bourdieu: reflexiones sobre educación. Revista Reflexiones, Facultad de Ciencias Sociales, 88(01), 155-162. Universidad de Costa Rica. 
Morales Zúñiga, Luis Carlos. (2010). Balance de la sociología de la educación en Costa Rica. Revista Reflexiones, Facultad de Ciencias Sociales, 89(01), Universidad de Costa Rica.

Morales Zúñiga, Luis Carlos. (2012). South Park: crítica del pensamiento crítico. Revista Reflexiones, Facultad de Ciencias Sociales, 91(02), Universidad de Costa Rica.

Schopenhauer, Arthur. (1960). El mundo como voluntad y representación (2a. ed.). Madrid: Ediciones Aguilar.

Wacquant, Loic. (2006). Pensamiento crítico y disolución de la doxa. ANTIPODA, (2), 43-50.

Zizek, Slavoj. (2007). The Day After: An Interview with Slavoj Zizek. Fillip 5. Vancouver. 